\title{
Use of thiopurines in inflammatory bowel disease: an update
}

Arshdeep Singh ${ }^{1}$, Ramit Mahajan ${ }^{1}$, Saurabh Kedia ${ }^{2}$, Amit Kumar Dutta ${ }^{3}$, Abhinav Anand ${ }^{2}$, Charles N. Bernstein ${ }^{4}$, Devendra Desai ${ }^{5}$, C. Ganesh Pai ${ }^{6 \S}$, Govind Makharia ${ }^{2}$, Harsh Vardhan Tevethia ${ }^{7}$, Joyce WY Mak $^{8}$, Kirandeep Kaur ${ }^{9}$, Kiran Peddi $^{10}$, Mukesh Kumar Ranjan ${ }^{2}$, Perttu Arkkila ${ }^{11}$, Rakesh Kochhar ${ }^{12}$, Rupa Banerjee ${ }^{7}$, Saroj Kant Sinha ${ }^{12}$, Siew Chien $\mathrm{Ng}^{8}$, Stephen Hanauer ${ }^{13}$, Suhang Verma ${ }^{12}$, Usha Dutta ${ }^{12}$, Vandana Midha ${ }^{14}$, Varun Mehta ${ }^{1}$, Vineet Ahuja ${ }^{2}$, Ajit Sood ${ }^{1}$

${ }^{1}$ Department of Gastroenterology, Dayanand Medical College and Hospital, Ludhiana; ${ }^{2}$ Department of Gastroenterology and Human Nutrition, All India Institute of Medical Sciences, New Delhi; ${ }^{3}$ Department of Gastroenterology, Christian Medical College, Vellore, India; ${ }^{4}$ University of Manitoba IBD Clinical and Research Centre, Max Rady College of Medicine, Rady Faculty of Health Sciences, University of Manitoba, Winnipeg, MB, Canada, ${ }^{5}$ P. D. Hinduja Hospital and Medical Research Centre, Mumbai, ${ }^{6}$ Department of Gastroenterology, Kasturba Medical College, Manipal; ${ }^{7}$ Asian Institute of Gastroenterology Hyderabad, Hyderabad, India; ${ }^{8}$ Department of Medicine and Therapeutics, Faculty of Medicine, The Chinese University of Hong Kong, Shatin, Hong Kong; ${ }^{9}$ Department of Pharmacology, Dayanand Medical College and Hospital, Ludhiana; ${ }^{10}$ Citizens Centre for Digestive Disorders, Hyderabad, India; ${ }^{11}$ Department of Gastroenterology, Helsinki University Central Hospital, Helsinki, Finland; ${ }^{12}$ Department of Gastroenterology, Postgraduate Institute of Medical Education and Research, Chandigarh; India; ${ }^{13}$ Department of Medicine, Northwestern University, Chicago, IL, USA; ${ }^{14}$ Department of Internal Medicine, Dayanand Medical College, Ludhiana, India

Inflammatory bowel disease (IBD), once considered a disease of the Western hemisphere, has emerged as a global disease. As the disease prevalence is on a steady rise, management of IBD has come under the spotlight. 5-Aminosalicylates, corticosteroids, immunosuppressive agents and biologics are the backbone of treatment of IBD. With the advent of biologics and small molecules, the need for surgery and hospitalization has decreased. However, economic viability and acceptability is an important determinant of local prescription patterns. Nearly one-third of the patients in West receive biologics as the first/initial therapy. The scenario is different in developing countries where biologics are used only in a small proportion of patients with IBD. Increased risk of reactivation of tuberculosis and high cost of the therapy are limitations to their use. Thiopurines hence become critical for optimal management of patients with IBD in these regions. However, approximately one-third of patients are intolerant or develop adverse effects with their use. This has led to suboptimal use of thiopurines in clinical practice. This review article discusses the clinical aspects of thiopurine use in patients with IBD with the aim of optimizing their use to full therapeutic potential. (Intest Res 2022;20:11-30)

Key Words: Inflammatory bowel disease; Azathioprine; Mercaptopurine; 6-Thioguanine; Developing countries

\section{INTRODUCTION}

Inflammatory bowel disease (IBD), once considered a disease

Received December 4, 2020. Revised February 19, 2021. Accepted March 1, 2021 Correspondence to Ajit Sood, Department of Gastroenterology, Dayanand Medical College and Hospital, Ludhiana 141001, Punjab, India. Tel: +919815-400-718, Fax: +91-161-2302620, E-mail: ajitsood10@gmail.com ${ }^{5}$ Current affiliation: Kuwait Hospital, Sharjah, United Arab Emirates. of the Western hemisphere, has emerged as a global disease. ${ }^{1}$ Corticosteroids, 5-aminosalicylates (5-ASA) and immunosuppressive agents, such as thiopurines have been the standard of care for patients with IBD for decades. With greater understanding of the pathological mechanisms involved in IBD, newer therapeutic agents have been developed; the most important being biologics and small molecules. Though these agents have improved the quality of life and reduced the need 
for hospitalization and surgery, they are far from providing a cure and do not guarantee total disease clearance. In addition, an increased risk of reactivation of tuberculosis/other infections and high cost of therapy with biologics are major barriers to their widespread use in developing countries. Thiopurines are probably the most cost-effective alternative for immune-suppression in resource limited settings, but the full potential of these drugs has not been tapped for the fear of intolerance and adverse effects. ${ }^{2}$ This update intends to summarize various aspects about the use of thiopurines in patients with IBD, so as to optimize their use in clinical practice.

\section{METABOLISM OF THIOPURINES}

Thiopurines include azathioprine (AZA), 6-mercaptopurine (6-MP) and 6-thioguanine (6-TG). These drugs lack intrinsic immune-suppressive properties and therefore metabolic transformations to active metabolites are crucial for their action. AZA is non-enzymatically converted into 6-MP. However, there is some evidence that glutathione-S-transferase may participate in this conversion. ${ }^{3} 6$-MP is then metabolized into 6-thioinosine-monophosphate (6-TIMP) (via hypoxanthineguanine phosphoribosyl transferase [HGPRT]). 6-TIMP is converted to 6-thioguanine monophosphate (6-TGMP) by inosine monophosphate dehydrogenase and guanosine monophosphate synthetase. 6-TGMP via phosphorylation is converted into 6-thioguanine diphosphate (6-TGDP) and 6-thioguanine triphosphate (6-TGTP). Together, 6-TGMP, 6-TGDP and 6-TGTP form the total pool of 6-thioguanine nucleotides (6-TGN). 6-TG metabolism is less complex as the enzyme HGPRT acts directly on 6-TG to generate 6-TGN. There is also some evidence to suggest that conversion of 6-TG to 6-TGN might be effected by gut microbiota. ${ }^{4}$

6-TGTP, the final product of thiopurine metabolism, is reduced to deoxy-thioguanosine triphosphate (TdGTP) and gets incorporated into double stranded DNA leading to mutagenesis and/or cell death. ${ }^{4}$

6-MP, as parent molecule or as a metabolite of AZA, can also undergo methylation by the enzyme thiopurine-S-methyltransferase (TPMT) forming 6-methylmercaptopurine (6MMP, inactive metabolite). TPMT can also methylate 6-TIMP to 6-methyl TIMP and lead to formation of 6-MMP ribonucleotides (active metabolite, 6-MMPR) which are responsible for hepatotoxic effects of thiopurines. Hence when TPMT activity is low, there is a risk of increased levels of 6-TGN. On the other hand, when TPMT enzyme activity is normal or high, elevated levels of methylated metabolites are present; thus, resulting in subtherapeutic levels of 6-TGN.

Nucleoside diphosphate-linked moiety X-type motif 15, encoded by NUDT15 gene, hydrolyses TdGTP and TGTP. Polymorphisms in NUDT15 (p.Arg139Cys [R139C], p.Arg139His, p.Val18Ile, p.Val18_Val19insGlyVal, etc.) therefore result in loss of diphosphatase activity, accumulation of 6-TGTP and TdGTP, and thiopurine-induced leucopenia.

The metabolic pathway of thiopurines and mechanisms of action are described in Fig.1.

\section{EVIDENCE FOR EFFICACY OF THIOPURINES IN} IBD

\section{Crohn's Disease \\ 1) Induction of Remission in $C D$}

A Cochrane review of 13 randomized controlled trials (RCTs) including 1,211 patients evaluated the role of thiopurines in induction of clinical remission in active Crohn's disease (CD) and found only a modest difference in clinical remission rates between AZA/6-MP and placebo (relative risk [RR], 1.23; 95\% confidence interval [CI], 0.97-1.55). ${ }^{5}$ However when AZA was used in conjunction with infliximab (IFX) in the Study of Biologic and Immunomodulator Naïve Patients in Crohn's Disease (SONIC), greater rates of induction of remission were reported with combination therapy as compared to monotherapy with IFX or AZA. Combination therapy was also superior in achieving mucosal healing (43.9\% in patients receiving combination therapy vs. $30.1 \%$ and $16.5 \%$ in patients receiving IFX $[P=0.06]$ and AZA $[P<0.001]$ monotherapy respectively $).{ }^{6}$ Though ineffective as monotherapy for induction of remission due to slow onset of action, treatment with thiopurines should be initiated early, so that these achieve therapeutic efficacy by the time corticosteroids/biologics are either withdrawn or dose reduction is done.

\section{2) Maintenance of Corticosteroid-Free Remission in CD}

A pooled analysis of 6 studies in a Cochrane review showed that AZA (1.0-2.5 mg/kg/day) was superior to placebo for maintenance of corticosteroid-free remission over a period of 6-18 months, with a number needed to treat of 9 (RR, 1.19; 95\% CI, 1.05-1.34). ${ }^{7}$ In addition to being superior to budesonide for maintenance of clinical remission, thiopurines aid in achievement of both mucosal (83\% vs. $24 \%$; $P<0.0001)$ and histologic $(P<0.0001)$ healing. ${ }^{8}$ 


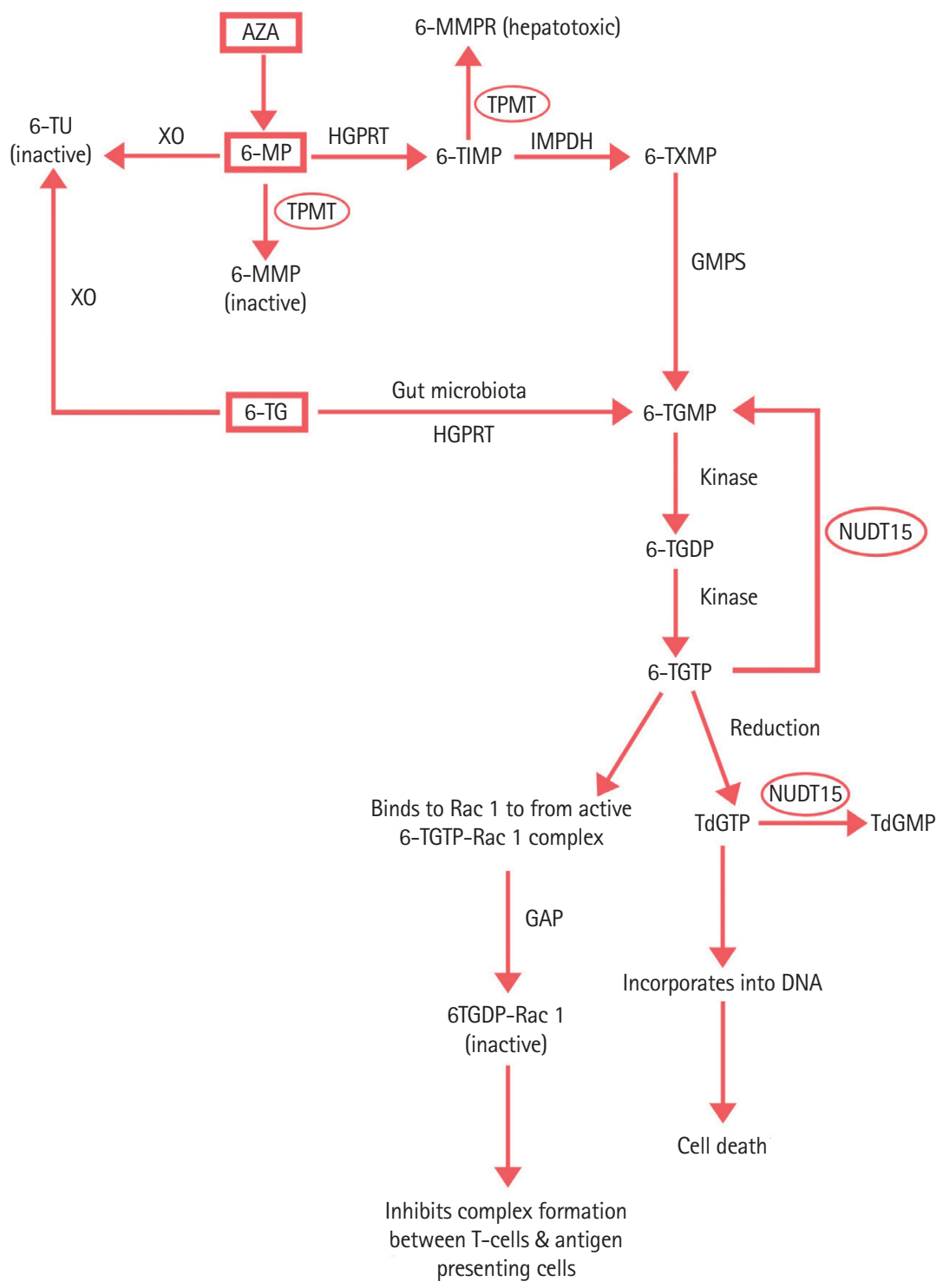

Fig. 1. Thiopurine metabolism. AZA, azathioprine; 6-MP, 6-mercaptopurine; 6-TU, 6-thiouric acid; 6-TIMP, 6-thioinosine monophosphate; 6-TXMP, 6-thioxanthinemonophosphate; 6-TGMP, 6-thioguanine monophosphate; 6-TGDP, 6-thioguanine diphosphate; 6-TGTP, 6-thioguanine triphosphate; TdGTP, deoxy-thioguanosine triphosphate; TdGMP, deoxy-thioguanosine monophosphate; 6-MMP, 6-methyl mercaptopurine; 6-MMPR, 6-methyl mercaptopurine ribonucleotides; 6-TG, 6-thioguanine; TPMT, thiopurine-S-methyltransferase; NUDT15, nucleoside diphosphate-linked moiety X-type motif $15 ; \mathrm{XO}$, xanthine oxidase; HGPRT, hypoxanthine-guanine phosphoribosyl transferase; GMPS, guanosine monophosphate synthetase; IMPDH, inosine monophosphate dehydrogenase; GAP, GTPase-activating protein.

\section{3) Postoperative CD}

Optimal use of thiopurines can prevent postoperative recurrence of CD. A network meta-analysis showed reduced risk of short-term (1 year) clinical and endoscopic recurrence with thiopurines. ${ }^{9}$ In a Cochrane review of 10 RCTs with 928 patients, AZA/6-MP was more efficient than placebo (3 studies, $51 \%$ vs. $64 \%$, RR, 0.79 ; $95 \%$ CI, $0.67-0.92$; moderate certainty evidence), had similar efficacy to 5-ASA (low certainty evidence) and was inferior to anti-tumor necrosis factor (TNF) agents (low certainty evidence) in prevention of surgical relapse. ${ }^{10}$ Risk stratification based on patient-related (age, sex, family history of IBD, smoker), disease-related (disease duration, disease location and behavior, perianal disease) and surgery-related (type of anastomosis, extent of resection, open vs. laparoscopic, prior surgery) factors is important for strategizing and personalizing postoperative management of $\mathrm{CD}$ to prevent recurrence. ${ }^{11}$ Younger patients ( $<30$ years of age), smokers, more than 2 prior surgeries, penetrating disease, 
perianal disease and shorter duration between diagnosis of $\mathrm{CD}$ and first surgery are risk factors for postoperative recurrence of $\mathrm{CD}$, and in such patients thiopurines should be started within 3 months of surgery.

\section{4) Fistulizing $C D$}

Initial studies assessing the role of AZA/6-MP in healing of fistulae found greater number of patients achieving fistula response with thiopurines as compared to placebo. ${ }^{12,13}$ Simple perianal fistulae (defined as intersphincteric or low transsphincteric fistula involving less than $30 \%$ of the external sphincter) ${ }_{1}^{14}$ especially refractory or recurrent, respond well to AZA/6-MP monotherapy. On the contrary, the benefit with thiopurines has not been documented in complex perianal fistulae (defined as fistula in high location [high intersphincteric, high transsphincteric, extrasphincteric, or suprasphincteric], anterior fistula in female patients, fistula with multiple external openings, or fistula associated with perianal abscess, anal stenosis, or proctitis). ${ }^{15}$ In patients with a concomitant active luminal disease, thiopurines should be used in combination with biologics. ${ }^{16,17}$ The data on the effects of thiopurines on internal fistulae are scarce.

\section{Ulcerative Colitis}

\section{1) Induction of Remission in UC}

There are a few studies evaluating the role of thiopurines in induction of remission in ulcerative colitis (UC). ${ }^{18-20}$ However there is remarkable heterogeneity in terms of number of patients, study design, dosage of thiopurines, duration of induction, evaluation of response and follow up. A systematic review and meta-analysis suggested a trend for benefit with thiopurine therapy in inducing remission but did not reach statistical significance (RR, 0.85; 95\% CI, 0.71-1.01). ${ }^{21}$ Thiopurine monotherapy is not recommended for induction of remission in UC.

Over the last decade, the use of combination therapy of thiopurines and anti-TNF agents for inducing remission has increased. The UC SUCCESS trial randomized patients with moderate to severe UC to IFX monotherapy, AZA monotherapy and combination therapy of IFX and AZA. At week 16, corticosteroid-free clinical remission was noted in $39.7 \%$ patients receiving combination therapy versus $22.1 \%$ and $23.7 \%$ patients receiving IFX and AZA respectively. ${ }^{22}$

\section{2) Maintenance of Remission in UC}

Thiopurines have been shown to be beneficial for the mainte- nance of remission in UC. ${ }^{23,24}$ A Cochrane review of 7 RCTs, based on use of thiopurines for a minimum of 12 months duration, found thiopurines to be significantly superior to placebo ( 4 trials, $56 \%$ vs. $35 \%$ ), mesalamine ( 1 trial, $50 \%$ vs. $0 \%$ ), and methotrexate ( 1 trial, $50 \%$ vs. $8 \%$ ) but not sulfasalazine ( $42 \%$ vs. $62 \%) .{ }^{24}$ Thiopurines are an effective maintenance therapy for patients who have failed or cannot tolerate mesalazine or sulfasalazine. ${ }^{24}$ They are also used as corticosteroid-sparing therapy in corticosteroid dependent disease, i.e. if a patient needs at least 2 courses of corticosteroid therapy in a calendar year. ${ }^{25,26}$ In addition, in patients with acute severe UC who require biologics or cyclosporine as a rescue therapy, the remission achieved by these agents can be maintained by thiopurines. ${ }^{27}$

The long-term efficacy of thiopurines was reported in 111 patients followed for $18.70 \pm 13.78$ months (range, $6-73$ months). The proportions of patients sustaining remission at $12,24,36$, 48 , and 60 months were $0.91,0.88,0.76,0.53$, and 0.38 respectively. ${ }^{28}$ In another study, 61 out of 71 patients (85.9\%) who received AZA for $>5$ years had sustained clinical benefit. ${ }^{29}$

\section{HOW TO USE THIOPURINES IN CLINICAL PRACTICE?}

Patients receiving thiopurines are prone to develop adverse effects or therapeutic resistance. It is therefore essential to evaluate each patient before initiation of therapy, and also continue on-therapy monitoring. A practical approach to prescription and monitoring of IBD patients on thiopurines is suggested in Fig. 2.

\section{Pre-Therapy Patient Assessment}

The efficacy and safety of thiopurines depend on several factors. Recognition of patient demographics is important. Increasing age is associated with increased risk of adverse effects including infections and malignancies. Certain malignancies such as hepatosplenic T cell lymphoma (HSTCL) and systemic Epstein-Barr virus (EBV; infectious mononucleosis) related $\mathrm{T}$ cell lymphoma are more common in young adults. While males are at an increased risk of developing lymphoma; other adverse effects, pancreatitis in particular, are more common in females. Concomitant alcohol abuse increases the probability of hepatotoxicity whereas smoking is associated with pancreatitis. Elaborate clinical history and examination and laboratory evaluation (complete blood count [CBC], liver function tests, renal function tests, and blood glucose) for as- 

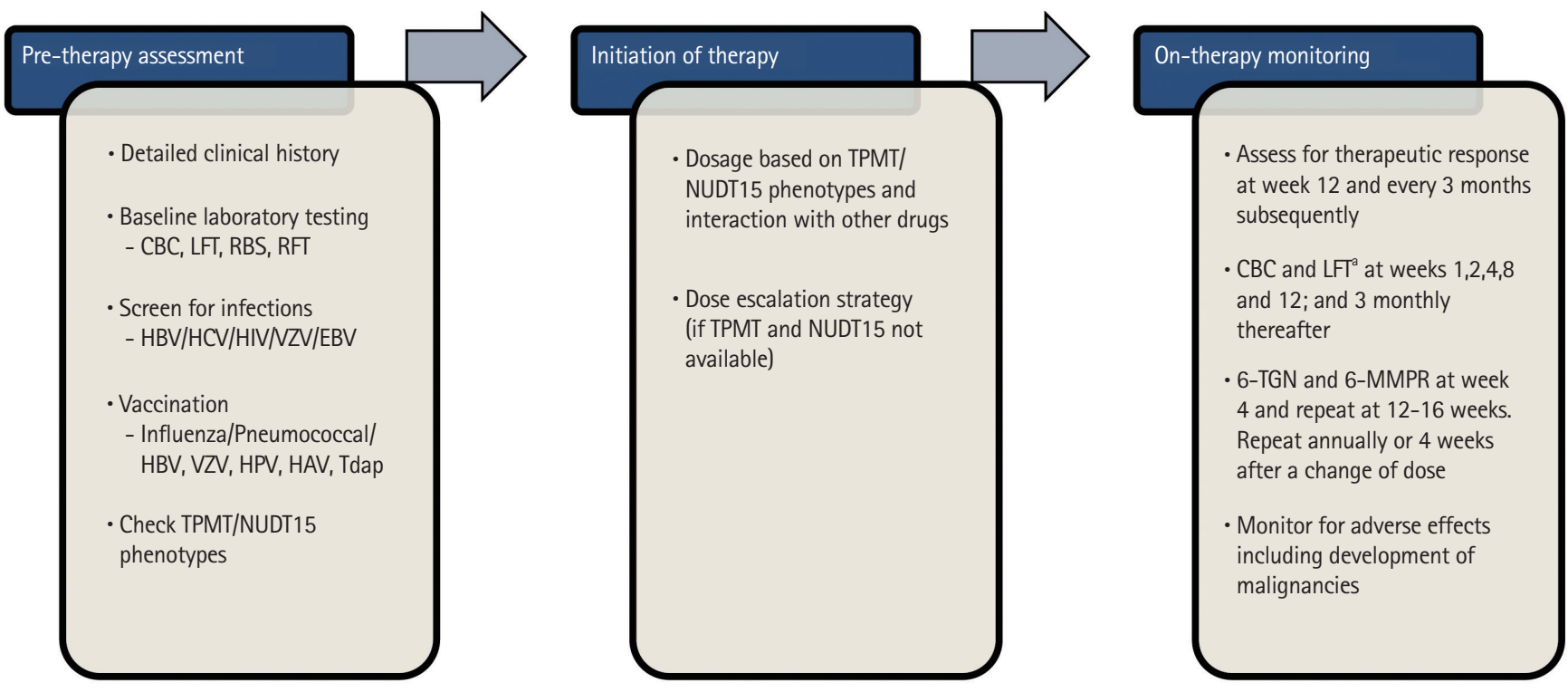

Fig. 2. An approach to initiation and monitoring of treatment with thiopurines. ${ }^{2}$ There are no definite recommendations for testing of liver functions or pancreatic enzymes, but this maybe done along with the CBCs. CBC, complete blood count; LF, liver function tests; RBS, random blood sugar; RF, renal function tests; HBV, hepatitis B virus; HCV, hepatitis C virus; HIV, human immunodeficiency virus; VZV, varicella zoster virus; EBV, Epstein-Barr virus; HPV, human papillomavirus; HAV, hepatitis A virus; Tdap, tetanus, diphtheria and pertussis; 6-MMPR, 6-methyl mercaptopurine ribonucleotide; 6-TGN, 6-thioguanine nucleotides; NUDT15, nucleotide diphosphate-linked moiety Xtype motif 15; TPMT, thiopurine-S-methyltransferase.

sessment of baseline parameters and co-morbid illnesses are essential (Table 1). Enquiring about history of blood transfusion in past 3 months is important as it may lead to falsely normal values of TPMT phenotypic estimations and impact initiating dose of thiopurines. ${ }^{30}$ Vaccination for vaccine-preventable diseases especially influenza, pneumococcal pneumonia, hepatitis B virus (HBV), varicella zoster virus (VZV), herpes zoster virus (HZV) and human papillomavirus (HPV) are recommended prior to initiation of therapy (discussed later) (Tables 1,2).

\section{1) Screening for Infections}

Screening for infections that may flare up with immune-suppression is important. The main infections that need to be screened are HBV, hepatitis C virus (HCV), human immunodeficiency virus (HIV), VZV and EBV.

Patients with active HBV infection (HBsAg and HBV DNA positive) should receive prophylactic antiviral therapy with nucleos(t)ide analogues, starting 1-2 weeks before commencing thiopurines and continue for at least 12 months after cessation of thiopurines. ${ }^{31}$ Presence of HCV is not an absolute contraindication to immunosuppressive therapy. Patients who fulfill the criteria for treatment of HCV should be treated with directly acting antivirals (DAAs). No clinically significant drug-drug interactions of thiopurines have been reported with DAAs. HIV-infected patients have low CD4 counts and theoretically have an increased risk (and severity) of infections. However, studies have shown that AZA can be safely used in patients receiving highly active antiretroviral therapy but close and careful monitoring is warranted. ${ }^{32}$

Thiopurines are contraindicated in presence of active infection with VZV. Those without a clear history of chickenpox, shingles or vaccination against VZV should be tested for VZV immunoglobulin G ( $\operatorname{IgG}$ ) antibodies. In seronegative patients, varicella vaccination should be completed at least 3 weeks before initiating thiopurines.

The use of thiopurines results in an immunocompromised state and increase the risk of developing either primary EBV infection (mononucleosis) or reactivation of latent EBV. Reactivation of EBV infection is associated with development of lymphoma in patients with prolonged use of thiopurines (discussed later). Primary EBV infection is also associated with an aggressive and often fatal form of post-mononucleosis lymphoma. ${ }^{33,34}$ Screening for EBV infection by EBV serology (EBNA IgG [EBV-determined nuclear antigen] and/or VCA IgG [viral-capsid antigen]) is therefore recommended before initiating therapy and thiopurines should be avoided in EBV seronegative patients. ${ }^{35}$ 
Table 1. Checklist for Evaluation of a Patient Prior to Initiation of Thiopurine Therapy

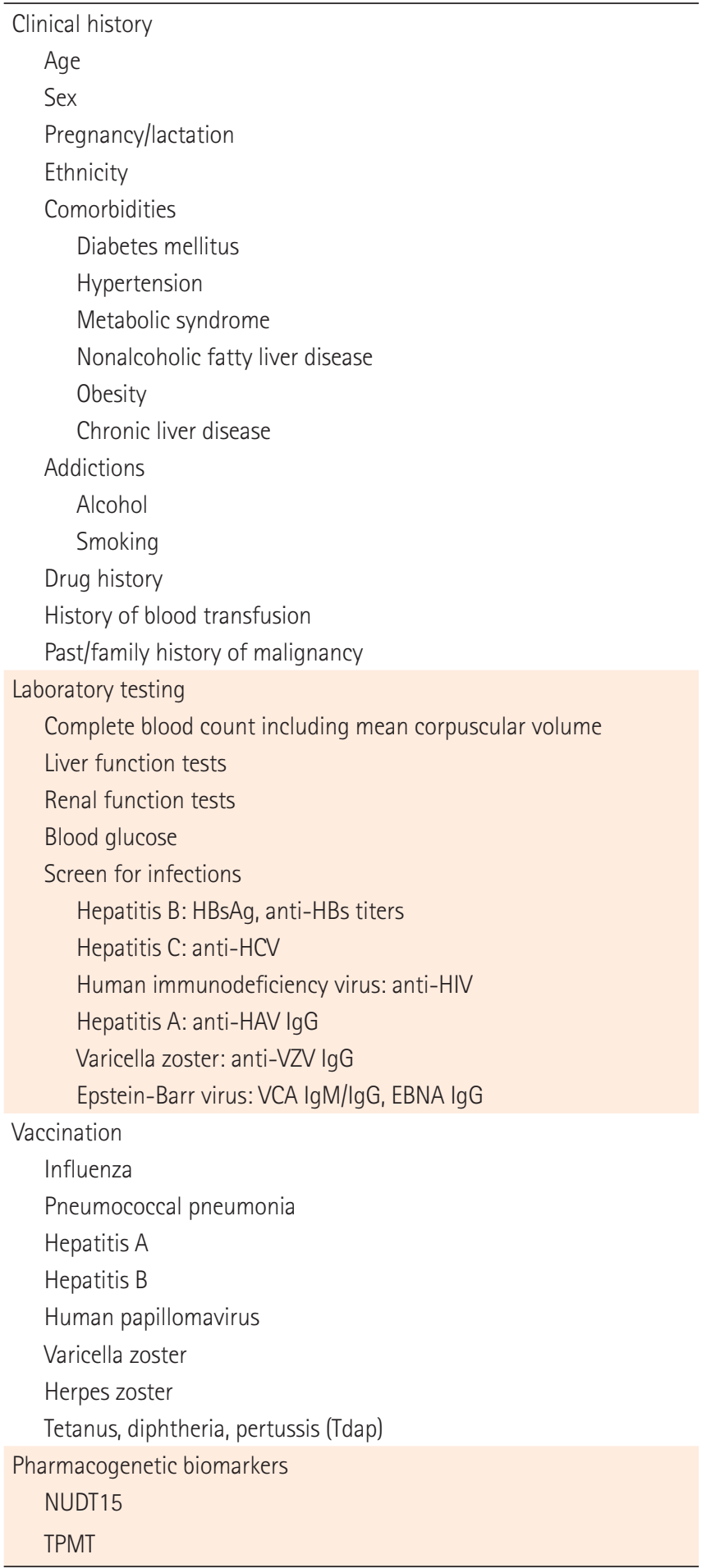

$\mathrm{HBsAg}$, hepatitis B surface antigen; anti-HBs, antibody to hepatitis B surface antigen; anti-HCV, antibody to hepatitis C virus; anti-HIV, antibody to human immunodeficiency virus; anti-HAV, antibody to hepatitis $A$ virus; IgG, immunoglobulin $\mathrm{G}$; anti-VZV, antibody to varicella zoster virus; VCA, viral-capsid antigen; EBNA, Epstein-Barr nuclear antigen; NUDT15, nucleotide diphosphate-linked moiety X-type motif 15; TPMT, thiopurineS-methyltransferase.

\section{2) Genetic Testing}

TPMT and NUDT15 are important determinants of thiopurine efficacy and toxicity. TMPT shunts the metabolism towards 6-MMP ribonucleotides (6-MMPR), and NUDT15 inactivates the activated 6-TGNs (Fig. 1). Mutations in these enzymes can lead to heterozygote/homozygote phenotype causing raised 6-TGN levels which are associated with myelosuppression.

More than 40 variant TPMT alleles (TPMT *2-*41) have been reported and most of these are associated with lower TPMT activity as compared with the wild allele (TMPT* 1 ). The major mutants resulting in reduced TPMT activity in most populations are TPMT*2, TPMT*3A and TPMT*3C. In clinical practice, both genotype and phenotype testing can be done. The phenotype testing determines the level of enzyme TPMT. An undetectable TPMT level is a contraindication to use of thiopurines whereas normal TPMT levels indicate low risk for adverse effects especially leucopenia. It is however important to understand that normal TPMT enzyme levels are no guarantee against adverse effects and leucopenia has been reported in individuals with normal TPMT levels. Although TPMT is the most frequently studied enzyme for predicting thiopurine toxicity worldwide, TPMT mutations have been infrequent and mainly heterozygous among Asians. Collie-Duguid et al. ${ }^{36}$ reported the frequency of TPMT genotype as $10.1 \%$ in Caucasians, $2.0 \%$ in South West Asians and $4.7 \%$ in Chinese populations, highlighting the ethnic differences in the mutation rates. ${ }^{36}$ Only about $6 \%$ of patients with IBD in Asia who develop thiopurine-induced leucopenia, carry TPMT mutations. ${ }^{37-40}$ In addition, homozygotes for TPMT mutant alleles are extremely rare $(\sim 0.01 \%)$ in Asians whereas their frequency is about $0.6 \%$ among Caucasians. ${ }^{38,41}$ NUDT15 R139C variants (CC: wild type, CT: heterozygote, and TT: homozygote) seem to play a more important role amongst Asians. In a systematic review and meta-analysis, the allelic frequency of NUDT15 R139C was $11.2 \%$ in Asian patients with IBD and there was a strong association between the NUDT15 R139C polymorphism and thiopurine-induced leucopenia. ${ }^{42}$

In patients with wild type TPMT/NUDT15, standard weightbased doses of thiopurines can be started. Use of thiopurines in heterozygote carriers is possible but these need to be started in a reduced dose (30\%-80\% of normal) $)^{43}$ Rarely patients can harbor both TPMT and NUDT15 risk variants. Dose of thiopurines in such patients is determined by the dominant variant. For example, if an individual is intermediate metabolizer (heterozygote) for TPMT and poor metabolizer (homo- 
Table 2. Vaccine Recommendations for Inflammatory Bowel Disease Patients Receiving Thiopurines

\begin{tabular}{|c|c|c|c|}
\hline Vaccine & Route & $\begin{array}{l}\text { Number of } \\
\text { doses }\end{array}$ & Comments \\
\hline Hepatitis B & Intramuscular & $\begin{array}{l}3 \text { doses } \\
(0,1,6 \text { months })\end{array}$ & Checking anti-HBs titer 1 month after the last dose may be useful \\
\hline Influenza & Intramuscular & 1 dose annually & Do not use live nasal vaccine \\
\hline Pneumococcus & Intramuscular & 1 or 2 doses & One time revaccination after 65 years of age (at least 5 years after last vaccination) \\
\hline Diphtheria, tetanus & Intramuscular & $\begin{array}{l}1 \text { dose every } 10 \\
\text { years }\end{array}$ & $\begin{array}{l}\text { First dose may be Tdap (Tetanus, diphtheria, acellular pertussis) instead of Td in patients } \\
<65 \text { years old }\end{array}$ \\
\hline Hepatitis A & Intramuscular & $\begin{array}{l}2 \text { doses } 6-12 \\
\text { months apart }\end{array}$ & A combination of hepatitis $A$ and $B$ vaccine is also available (dose at 0,1 and 6 months) \\
\hline Varicella & Intramuscular & $\begin{array}{l}2 \text { doses } 4-6 \\
\text { weeks apart }\end{array}$ & $\begin{array}{l}\text { Shingles (live vaccine) vaccine is distinct and more potent compared to varicella vaccine } \\
\text { and a single dose of vaccine administered subcutaneously is recommended in patients } \\
>60 \text { years of age }\end{array}$ \\
\hline Measles, mumps, rubella & Intramuscular & $\begin{array}{l}2 \text { doses } 4 \text { weeks } \\
\text { apart }\end{array}$ & Contraindicated during thiopurine therapy \\
\hline
\end{tabular}

anti-HBs, hepatitis B surface antibody.

Table 3. TPMT/NUDT Phenotype and Dose of Thiopurines in Inflammatory Bowel Disease

\begin{tabular}{ll}
\hline TPMT/NUDT15 phenotype & \multicolumn{1}{c}{ Starting doses of AZA/6-MP/6-TG } \\
\hline TPMT/NUDT15 wild type & Start with normal dose \\
TPMT/NUDT15 heterozygote & $\begin{array}{l}\text { Start with reduced dose (30\%-80\%). Dose adjustments to be made every 2-4 weeks } \\
\text { Close follow up for development of adverse effects (myelosuppression). If myelosuppression occurs, further reduce } \\
\text { the dose }\end{array}$ \\
TPMT/NUDT15 homozygote & Thiopurines are contraindicated; significant risk of myelosuppression \\
\hline
\end{tabular}

AZA, 6-MP, and 6-TG are used in doses of $1.5-2.5 \mathrm{mg} / \mathrm{kg}, 1.0-1.5 \mathrm{mg} / \mathrm{kg}$, and 0.2-0.3 $\mathrm{mg} / \mathrm{kg}$ respectively.

AZA, azathioprine; 6-MP, 6-mercaptopurine; 6-TG, 6-thioguanine; TPMT, thiopurine-S-methyltransferase; NUDT15, nucleoside diphosphate-linked moiety X-type motif 15.

zygote) for NUDT15, NUDT15 pharmacology will dictate the initiating dose and protocol, though the evidence remains limited. In TPMT and NUDT15 homozygotes, thiopurines are contraindicated because of increased risk of myelosuppression and alopecia (Table 3 ).

\section{3) Drug Interactions of Thiopurines}

Thiopurines have important drug interactions with other drugs that influence the dosage, clinical efficacy and potential adverse effects. Combination of thiopurines with 5-ASA has been tried for long in IBD patients to attain remission. There is a possible synergism between the 2 drugs as 5-ASA compounds inhibit TPMT enzyme activity. Therefore, co-prescription of thiopurines and 5-ASA is expected to increase active metabolites of thiopurine metabolism by directing metabolism of the drug towards the production of 6-TGN at a relatively lower prescribing dose of thiopurines. ${ }^{44,45}$ Allopurinol inhibits the activity of enzyme xanthine oxidase. Therefore, a com- bination of low dose thiopurines and allopurinol (LDTA) leads to higher levels of active metabolites, better clinical response, lower hepatotoxicity and better tolerance. ${ }^{46,47}$ Thiopurines also decrease the formation of anti-drug antibodies and improve the clinical efficacy of IFX. ${ }^{48}$

The important drug-drug interactions of thiopurines are summarized in Table 4.

\section{Initiating Therapy: How to Choose and What Dose?}

The efficacy and safety of all thiopurine agents (AZA, 6-MP, and 6-TG) is similar and the choice of agent depends on local prescribing preferences, physician and patient preference, availability and financial implications. The majority of physicians in India use AZA. ${ }^{23,28}$ A designer thiopurine analogue; B-0N, has also been developed using rational drug design. ${ }^{49}$ It mediates earlier and stronger induction of $\mathrm{T}$ cell apoptosis compared to 6-MP and is associated with fewer adverse effects in vitro, however further studies consolidating these 
Table 4. Important Drug Interactions of Thiopurines

\begin{tabular}{lll}
\hline Name of the drug & \multicolumn{1}{c}{ Possible mechanism } & Outcome \\
\hline $\begin{array}{l}\text { Allopurinol and Febuxostat } \\
\text { (XO inhibitors) }\end{array}$ & Inhibition of XO and shunting 6-MP to 6-TGN formation & Myelosuppression \\
5-Aminosalicylates & TPMT inhibition & Myelosuppression \\
Warfarin & Possibly increased metabolism/decreased absorption & Decreased warfarin efficacy \\
ACE inhibitors & Poorly understood & Myelosuppression and anemia \\
Loop diuretics & TPMT inhibition & Myelosuppression \\
Ribavirin & IMPDH inhibition & Myelosuppression \\
Chemotherapeutic agents & Likely additive effect on cytotoxicity of sinusoidal cells & Sinusoidal obstruction syndrome/veno-occlusive disease \\
\hline
\end{tabular}

$\mathrm{XO}$, xanthine oxidase; ACE, angiotensin converting enzyme; 6-MP, 6-mercaptopurine; 6-TGN, 6-thioguanine nucleotides; TPMT, thiopurine-S-methyltransferase; IMPDH, inosine monophosphate dehydrogenase.

promising early results are needed.

\section{Dosing Protocols}

\section{1) Standard Weight-Based Dose}

Dose recommendations for AZA and 6-MP vary slightly between guidelines. American Gastroenterological Association recommends a daily dose of $2-3 \mathrm{mg} / \mathrm{kg}$ AZA and $1-1.5 \mathrm{mg} / \mathrm{kg}$ 6-MP whereas European Crohn's and Colitis Organisation recommends a daily dose of $1.5-2.5 \mathrm{mg} / \mathrm{kg}$ AZA and $0.75-1.5$ $\mathrm{mg} / \mathrm{kg} 6-\mathrm{MP}^{16,50} \mathrm{The}$ dose of $6-\mathrm{TG}$ is $0.2-0.3 \mathrm{mg} / \mathrm{kg}^{51}$

\section{2) Dosing Protocols to Improve Tolerance of Thiopurines}

(1) Low dose

AZA when used at a dose $<2 \mathrm{mg} / \mathrm{kg}$ is generally labelled as low dose. ${ }^{52}$ Lower doses of AZA have been found to be effective for maintaining remission and having lesser risk of myelosuppression in Asians. ${ }^{27,52}$ A retrospective study from India reported that the mean dose of AZA to maintain steroid-free remission in patients with IBD was $1.48 \mathrm{mg} / \mathrm{kg} / \mathrm{day}$ (range, 0.59$3.77 \mathrm{mg} / \mathrm{kg} /$ day)..$^{53} \mathrm{~A}$ possible reason could be the co-prescription of 5-ASA, which inhibit TPMT enzyme activity and direct the metabolism of AZA/6-MP towards formation of 6-TGN. ${ }^{44}$ Lower doses of AZA are also used when prescribed in combination with IFX, or in patients who are intolerant to weightbased doses. ${ }^{54}$

\section{(2) Split dose}

Splitting the dose keeps the peak serum concentrations of AZA/6-MP below the threshold substrate affinity of TPMT. Twice daily administration of AZA/6-MP also decreases 6-MMPR levels with little impact on 6-TGN levels. Split-dose may thus be tried in patients with gastrointestinal intolerance to standard once-daily dosing or those with hepatotoxicity.
Dose splitting may allow for further upward titration of thiopurines, if needed. ${ }^{55}$

\section{(3) Incremental dose}

To avoid adverse effects like gastrointestinal intolerance; which are more pronounced early in the course of therapy and frequently result in drug withdrawal; thiopurines can be initiated at a low dose (25-50 mg/day) and gradually increased (usually by $25 \mathrm{mg}$ every $2-4$ weeks). This approach can also be an alternative to standard weight-based dosing protocols when pretherapy genetic testing or on-therapy metabolite monitoring (discussed later) are not available/affordable. ${ }^{56}$

\section{(4) Low dose thiopurine with allopurinol}

A subset of patients with high TPMT activity ( $>35 \mathrm{pmol} / \mathrm{hr} /$ mg of hemoglobin), known as "predominant methylators," metabolize thiopurines rapidly leading to suboptimal therapeutic response and predisposition to hepatotoxicity. ${ }^{57}$ Using low dose thiopurines (25\%-50\% of standard dose) and addition of $100 \mathrm{mg}$ of allopurinol (which decreases thiopurine metabolism by inhibiting xanthine oxidase) corrects hypermethylation in such patients. This combination therapy leads to increased levels of active metabolites (6-TGN) as well as lower rates of thiopurine-induced hepatotoxicity and therefore better tolerance. However, there is an increased risk of leucopenia which needs close monitoring. Additionally, risks of adverse effects associated with allopurinol such as toxic epidermal necrolysis, fever, gastrointestinal intolerance, hematuria and hepatotoxicity need monitoring.

\section{Combination Therapy of Thiopurines and Anti-TNF Agents}

Combination therapy of thiopurines has been extensively 
studied with IFX, both in CD and UC. ${ }^{6,22,58}$ Chimeric anti-TNF agents like IFX have the ability to stimulate immune system resulting in formation of antibodies against the drug (antibodies to IFX, ATI); thereby decreasing the trough levels and hence clinical efficacy. ${ }^{48}$ ATIs also increase the risk of developing infusion reactions. Addition of thiopurines to IFX modulates the immunogenicity of IFX and reduces the formation of ATIs. The evidence regarding clinical benefit of combination therapy for adalimumab is weak as compared to IFX. However, combination therapy of adalimumab and thiopurines in the DIAMOND study resulted in higher trough levels of adalimumab, though clinical remission was not superior with combination therapy as compared to monotherapy. ${ }^{58}$ There is no evidence to suggest benefit of combining thiopurines with vedolizumab or ustekinumab.

Patients who achieve corticosteroid-free remission with combination therapy (IFX+AZA) and maintain it for 6-12 months can be considered for withdrawal of one of the agents. Studies have assessed stopping either thiopurines or IFX and reported mixed results. While some did not favor continuation of thiopurines beyond 6 months as it did not offer benefit over-scheduled biologic therapy, others suggested continuation of thiopurines in reduced doses (rather than complete cessation) until 1 year after achievement of remission for continuous benefit. ${ }^{59,60}$ Stopping IFX and continuing with thiopurines has been reported to have high cumulative relapse rates. However, complete mucosal healing at the time of IFX cessation is associated with fewer relapses and similar long-term remission rates as with thiopurine withdrawal. ${ }^{61}$ For resource constrained countries like India; where maintenance therapy with biologics is not an economically viable option and also carries the risk of reactivation of latent tuberculosis; stopping biologics and continuing thiopurines can be considered as an option. Large prospective studies are however needed to assess the safety and efficacy of this approach.

\section{THERAPEUTIC DRUG MONITORING}

Patients receiving thiopurines need to be closely monitored for therapeutic response and adverse effects. The standard procedures for monitoring efficacy and safety of thiopurines are based on monitoring of therapeutic drug metabolites. Several studies and a meta-analysis have shown that therapeutic efficacy of thiopurines correlates with the concentration of 6-TGN (235-450 pmol/8× $\left.10^{8} \mathrm{RBCs}\right)$. However when combination therapy of IFX and AZA is used, even lower 6-TGN levels ( $>125 \mathrm{pmol} / 8 \times 10^{8} \mathrm{RBCs}$ ) may correlate with therapeutic efficacy. Risk of myelosuppression is greater with 6-TGN $>450$ $\mathrm{pmol} / 8 \times 10^{8} \mathrm{RBCs}$, while hepatotoxicity is related to 6 -MMPR levels of $>5,700 \mathrm{pmol} / 8 \times 10^{8} \mathrm{RBCs}^{62,63}$ Table 5 shows the interpretation for thiopurine metabolite estimation.

Whether the monitoring of metabolites should be pro-active or reactive is a matter of debate. However, "reactive approach" (i.e., monitoring metabolites in patients with treatment failure or adverse effects) is a more conventional approach. ${ }^{64}$ Evidence suggests that $80 \%-90 \%$ of patients had improved clinical outcomes when their dose was optimized based on 6-TGN levels. ${ }^{65}$ Patients who have metabolites within normal levels but have active disease can be labelled as treatment refractory. Thiopurine metabolites should be measured 4 weeks after dose modification, and every 12 weeks subsequently until an adequate therapeutic level is achieved. ${ }^{66}$ However it may take longer in pediatric population (up to 55 days) to achieve steady state.

Regular CBC is required to monitor for myelotoxicity. CBC will also provide information about changes in mean corpuscular volume (MCV), which could be a surrogate marker for therapeutic drug monitoring. MCV increases in response to thiopurines because of accumulation of metabolites in red blood cells (RBCs) and megaloblastic erythropoiesis due to inhibition of DNA synthesis. In patients adherent to thiopurine therapy, MCV values increase and stabilize after 3-6

Table 5. Interpretation of Thiopurine Metabolites

\begin{tabular}{llll}
\hline $\begin{array}{c}\text { 6-TGN level } \\
\left.\text { (pmol/8 } \times 10^{8} \mathrm{RBCs}\right)\end{array}$ & $\begin{array}{c}\text { 6-MMPR level } \\
\left(\mathrm{pmol} / 8 \times 10^{8} \mathrm{RBCs}\right)\end{array}$ & Interpretation & Change in therapy \\
\hline $235-450$ & $<5,700$ & Normal levels & None \\
Undetectable & Undetectable & Non adherence & Counselling \\
$<235$ & $<5,700$ & Subtherapeutic & Increase the dose \\
$>450$ & Low, normal or high & Supratherapeutic & Reduce the dose \\
$<235$ & $>5,700$ & Shunter to 6-MMPR with risk of hepatotoxicity & Reduce AZA and add allopurinol \\
\hline
\end{tabular}

6-TGN, 6-thioguanine nucleotides; 6-MMPR, 6-methyl mercaptopurine ribonucleotides; RBCs, red blood cells; AZA, azathioprine. 
months of treatment initiation. Multiple cohort studies have demonstrated a correlation between RBC 6-TGN levels and MCV. An increase in MCV by $\geq 7 \mathrm{fL}$ or MCV $\geq 101 \mathrm{fL}$ is fairly suggestive of therapeutic 6-TGN levels. ${ }^{67,68}$

\section{DEFINING THIOPURINE FAILURES}

Studies have demonstrated that time taken for clinical and endoscopic response to thiopurines is usually $3-6$ months. ${ }^{6,13}$ In clinical practice, response to thiopurines is dependent on optimized (normal thiopurine metabolites) use of thiopurines. Thiopurine refractoriness should therefore be considered when there is lack of clinical benefit despite full optimization of therapy. Thiopurine nonresponse was defined as signs and symptoms of persistently active disease despite a history of $\geq 18$-week regimen in GEMINI 1 trial. ${ }^{69}$ Failure to produce therapeutic response after 4-6 months of fully optimized therapy may be labelled as thiopurine ineffectiveness. ${ }^{70}$

\section{SAFETY OF THIOPURINE THERAPY}

The adverse effects associated with thiopurines may be divided into 2 categories: (1) dose-dependent and (2) idiosyncratic reactions. The dose-dependent adverse effects are predictable, pharmacologically explainable and occur due to production of thiopurine metabolites. They can occur at any time after starting the therapy and can be successfully prevented and treated by dose reduction. Idiosyncratic reactions are unpredictable, dose-independent and include allergic reactions (flu like symptoms, fever, rash, and arthralgia) and pancreatitis. Up to $5 \%-10 \%$ of patients are unable to tolerate thiopurines at any dose due to idiosyncratic reactions that typically occur within 2-4 weeks of therapy initiation. ${ }^{4}$

\section{Leucopenia}

Myelosuppression is the commonest (2\%-12\%) dose-dependent adverse effect and the most common cause of drug discontinuation. The presentation is usually with leucopenia, although other cell lines may also be suppressed in conjunction (anemia, thrombocytopenia). A decline in leukocyte count within 1-2 weeks of therapy may be a marker of impending leucopenia. Although myelosuppression can occur at any time, severe myelosuppression is less frequent after the first 8 weeks of therapy.

The TPMT and NUDT15 variants are associated with increased risk of leucopenia. As discussed earlier, the frequency of TMPT risk alleles is low in Asians. NUDT15 variant is more common in Asia, especially Eastern and South-Eastern countries. The frequency of CC, CT, and TT alleles in East Asians is approximately $80 \%, 20 \%$, and $1 \%$, respectively. ${ }^{71}$ Early leucopenia occurs in less than $3 \%$ of patients with CC, $20 \%$ of patients with CT, and almost all patients with TT alleles of NUDT15 R139C gene variant. Testing for NUDT15 R139C variant, especially in Asians, can help prevent leucopenia and personalize the use of thiopurines. However, the application of genetic testing before starting thiopurines in real life situations is still limited owing to its high costs. Additionally leucopenia can also occur despite normal TPMT activity. Therefore, regular monitoring of CBC (every week for first 2 weeks, fortnightly for next 2 weeks, monthly till week 12, and 3 monthly thereafter) is required, even if pre-therapy genetic testing has been performed. $^{4}$

Development of leucopenia early in the course of therapy warrants dose modification and/or withdrawal of therapy with reintroduction at lower doses once the blood counts have normalized. As 6-TGNs are the common final metabolite with AZA, 6-MP, and 6-TG, use of one drug over the other does not carry any benefit.

\section{Hepatotoxicity}

The spectrum of thiopurine-induced liver injury includes hypersensitivity reaction (acute hepatitis), cholestasis (mixed or bland) and endothelial injury (veno-occlusive disease, peliosis hepatis and nodular regenerative hyperplasia). While hypersensitivity and cholestasis are idiosyncratic reactions, occurring early; injury mediated by endothelial cell damage is considered to be dose-dependent and a late event. ${ }^{72}$

The most common form of thiopurine-induced liver injury is transient asymptomatic elevation of liver enzymes, which requires continuation of therapy with close monitoring. At times persistently rising liver enzymes warrant dose reduction and/or discontinuation of therapy. ${ }^{73}$ Split-dosing and LDTA are other possible strategies to overcome asymptomatic TPMT-related elevation of liver enzymes.

The acute cholestatic injury due to AZA usually presents with fatigue and jaundice, pruritis is uncommon. Cholestatic hepatic injury usually resolves on stopping the drug, but rarely it can be prolonged or culminate into vanishing bile duct syndrome. ${ }^{74}$ Endothelial injury to liver manifests as fatigue with signs and symptoms of hepatic parenchymal injury and portal hypertension. In cases of veno-occlusive disease an acute presentation with abdominal pain and ascites can be seen. Bio- 
chemically, minimal elevation of liver enzymes, hyperbilirubinemia and evidence of hepatic dysfunction and portal hypertension are evident. Continuation of thiopurines in patients with endothelial injury is contraindicated as it may progress to end stage liver disease. Withdrawal of thiopurines usually reverses the hepatic injury. ${ }^{75}$ Some patients who develop hepatotoxicity with AZA/6-MP may tolerate 6-TG in smaller doses. However more data is required before this can be recommended.

\section{Acute Pancreatitis}

Acute pancreatitis is an idiosyncratic complication reported in about 3\% of patients. The episodes are usually mild; female sex and smoking being the probable risk factors. ${ }^{76,77} 6$-MP should not be used in patients with AZA-induced pancreatitis. However, 6-TG (at doses of 20-40 mg) maybe a safer alternative to AZA/6-MP for patients who are at high risk of AZA/6MP induced acute pancreatitis. ${ }^{78}$

\section{Gastrointestinal Intolerance}

Nausea, vomiting and, rarely, diarrhea and pain abdomen are side effects of thiopurines encountered during initial few weeks. These are usually self-limiting. Successful shifting from AZA to 6-MP or 6-TG in such patients has been reported. ${ }^{79}$

\section{Infections}

Immunosuppressive actions of thiopurines affect both innate and acquired immune systems, thus increasing the risk of opportunistic as well as non-opportunistic infections. Concomitant use of other immunosuppressive drugs further accentuates the risk. ${ }^{80}$ The risk of opportunistic infections was markedly increased if thiopurines were used in combination with systemic steroids as compared to monotherapy with thiopurines (odds ratio [OR],17.5; 95\% CI, 4.5-68 and OR, 3.8; 95\% CI, $2.0-7.0$, respectively). ${ }^{81}$ A meta-analysis showed that the combination of thiopurine and anti-TNF therapy increased the risk of serious infections compared to monotherapy with thiopurines (hazard ratio, 2.11 ; 95\% CI, $1.80-2.48$ ) ${ }^{80}$ Serious infections mainly involved the respiratory tract, gastrointestinal tract, and skin. Opportunistic infections with viruses (varicella, cytomegalovirus, EBV, etc.), bacteria and mycobacteria have been encountered with increased frequency with use of thiopurines ${ }^{80}$ Pre-therapy screening for HBV, HCV, HIV, varicella and tuberculosis is therefore recommended ${ }^{82}$ Patients should be sensitized to seek help promptly in case of fever or suspected infection to ensure early detection, diagnosis and treat- ment. Close contact with other patients suffering from contagious diseases should be avoided. Inadvertent exposures should be reported as soon as possible so that post-exposure prophylaxis may be undertaken when indicated.

The common adverse effects noticed with thiopurines and their management are summarized in Table 6.

\section{RISK OF MALIGNANCY}

The use of thiopurines has been associated with an increased risk of both non-Hodgkin and Hodgkin lymphoma. Nearly $50 \%$ of IBD patients who develop lymphoma on immunosuppressive therapy are EBV seropositive. Such lymphomas resemble post-transplant lympho-proliferative disorders and are commonly of B cell type. A recent meta-analysis of 18 studies provided a pooled standardized incidence ratio of 4.92 (95\% CI, 3.10-7.78) for development of lymphoma. The highest absolute risk for thiopurine associated lymphoma was in people older than 50 years of age. The age-adjusted risk of lymphoma was higher during exposure to the drug, and reduced to that of the general population once the drug was discontinued. ${ }^{83}$ However a recent analysis of Japanese administrative database did not demonstrate an increased risk of lymphoma with thiopurines, whether used alone or in combination with antiTNF agents. The ethnic differences in the risk of developing lymphoma with thiopurines nevertheless warrant further evaluation. ${ }^{84}$

Patients seronegative for EBV can develop primary EBV infection (mononucleosis) while being on thiopurines. Fatal forms of post-mononucleosis $\mathrm{T}$ cell lymphoma, associated with hemophagocytic lymphohistiocytosis, have been reported, particularly in children and adolescents. ${ }^{33,34}$ Thiopurine use should therefore be limited in EBV seronegative patients due to increased risk of post-mononucleosis lymphoproliferative disorders.

Another type of lymphoma associated with thiopurines is HSTCL, which is a non-EBV related, typically fatal extra-nodal lymphoma of peripheral T cells of $\gamma \delta$ phenotype. Patients present with constitutional symptoms (fever, weight loss, and fatigue) and hepato-splenomegaly. The risk of developing HSTCL on thiopurines is estimated to be small $(<1: 20,000$ personyears) and is highest in young males receiving combination therapy of anti-TNF agents and thiopurines for longer duration (usually $\geq 2$ years). ${ }^{85}$

In a prospective observational study from France, patients with past exposures to thiopurines had a 7 -fold increased risk 
of myeloid disorders especially acute myeloid leukemia. Interestingly, the risk of myeloid disorders was not increased among patients with ongoing thiopurine treatment. The absolute risk of myeloid disorder was only $1 / 10,000$. The risk therefore needs to be balanced against the benefits of thiopurines in patients with IBD. ${ }^{86}$

Thiopurines have also been associated with the occurrence of melanoma and nonmelanoma skin cancers (NMSC). Rates of NMSC, which includes basal cell cancer and squamous cell cancer, are higher than melanoma and increase with longer duration of use. ${ }^{87}$ Cancers of urinary tract and uterine cervix have also been reported. ${ }^{88,89}$

In patients with previous history of malignancy thiopurines can be considered after 2 years of completion of cancer treatment with documented evidence of complete cure of cancer. For cancers with high risk of recurrence, the interval can be extended up to 5 years. However, history of previous EBV related malignancy is a contraindication to reuse of thiopurines. For patients developing a new malignancy while on treatment with thiopurines, thiopurines need not be stopped if the newly diagnosed malignancy can be resected with tumor-free margins. If chemotherapy/radiotherapy is indicated and the malignancy is not amenable to complete surgical resection, thiopurines should be withdrawn. Table 7 describes the protocols for screening and monitoring for malignancies in patients receiving thiopurines.

Table 6. Management of Adverse Effects Associated with Thiopurines

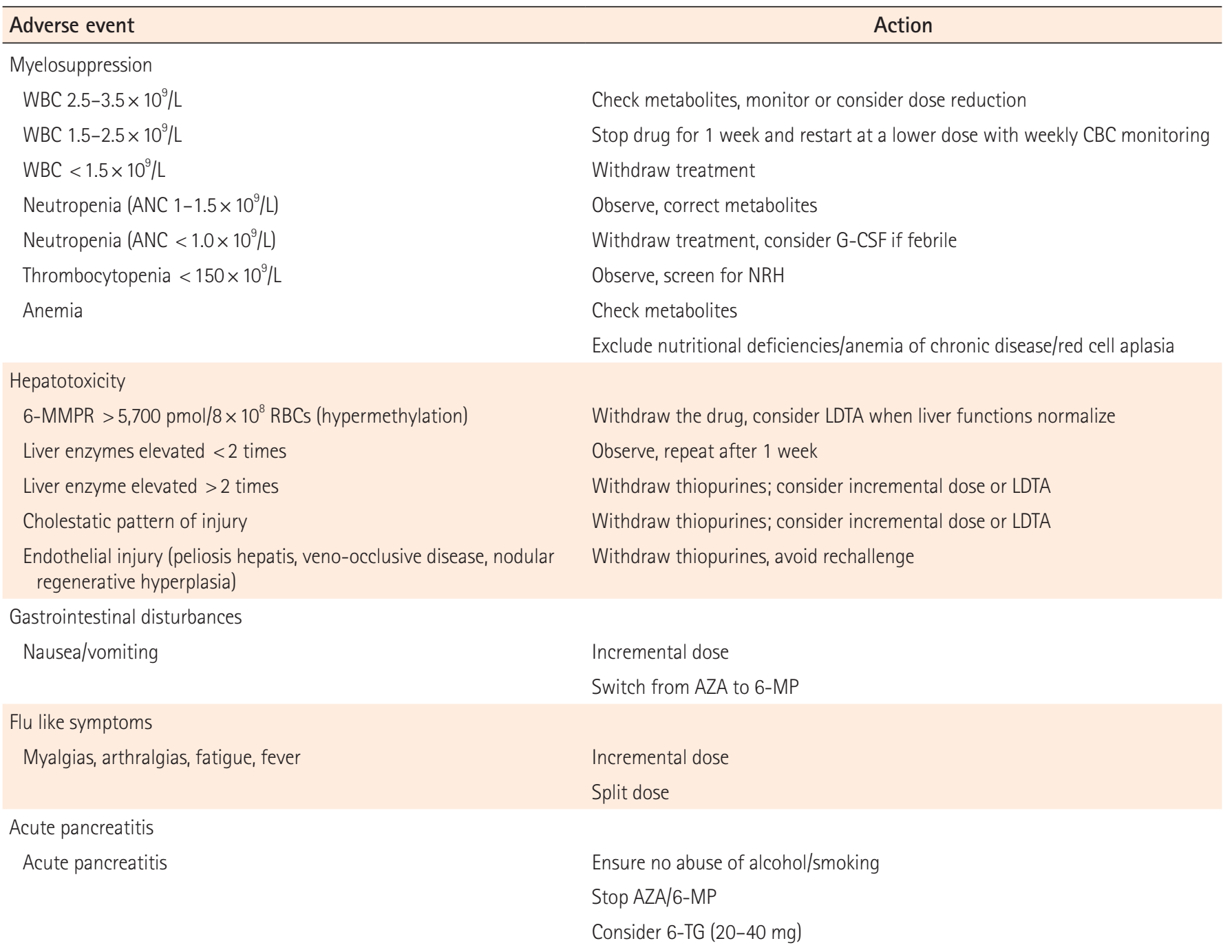

WBC, white blood cells; ANC, absolute neutrophil count; $C B C$, complete blood count; G-CSF, granulocyte-colony stimulating factor; NRH, nodular regenerative hyperplasia; 6-MMPR, 6-methyl mercaptopurine ribonucleotide; RBC, red blood cells; LDTA, low dose thiopurines with allopurinol; AZA, azathioprine; 6-MP, 6-mercaptopurine; 6-TG, 6-thioguanine. 


\section{USE OF THIOPURINES IN SPECIAL SITUATIONS}

\section{Pregnancy}

Thiopurines, being teratogenic in animals (previously labelled as Food and Drug Administration [FDA] class D), are of concern for their use in pregnancy and lactation. AZA crosses placenta and its metabolites are present in fetal RBCs. Meta-analyses have found no increase in the risk of low birth weight or congenital anomalies with use of thiopurines in pregnancy; however the risk of preterm birth was higher. ${ }^{90,91}$ The risk of preterm birth was proposed to be associated with IBD activity rather than thiopurines in a large Swedish registry. ${ }^{92}$ Therefore, continuation of pre-conception therapy with thiopurines for maintaining remission during pregnancy is safe and recommended. Infants born to mothers receiving thiopurines in combination with biologics have an increased risk of infections and cessation of one of the 2 drugs, usually thiopurines, should be considered.$^{92}$ Also LDTA should not be used because of teratogenic risks of allopurinol. Initiating thiopurines for the first time in pregnancy is not recommended due to uncertainty of complications and delayed therapeutic response. ${ }^{72}$

\section{Lactation}

Assessment of long-term outcomes in babies born to mothers taking AZA during pregnancy or lactation showed no increased risk of infections. Therefore, breast feeding can be allowed during maintenance therapy with AZA. The major part of thiopurines in breast milk is excreted within the first 4 hours after drug intake and the maximum exposure of the drug to the infant is less than $1 \%$ of the maternal dose. Therefore the lactating mother should breastfeed at least 4 hours after the drug ingestion to reduce the infant's drug exposure. The practice of "pumping and dumping" 4 hours breast milk is neither necessary nor likely to be effective and should be discour-

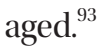

\section{Elderly Population}

The number of elderly with IBD is increasing worldwide due to longevity of survival of patients with adult-onset IBD or due to development of elderly-onset IBD. Among the elderly IBD patients, UC (E2>E3) is more common than CD (colonic > ileal). Thiopurines, when used for maintenance of remission in elderly, are well tolerated and have been shown to be as efficacious as in younger IBD patients. However, associated comorbidities limit their use (drug-drug interactions). Elderly patients are also at an increased risk of adverse effects, including infections, and malignancies. Therefore, the long-term use of thiopurines in elderly should be considered carefully, weighing risks versus benefits. ${ }^{94}$

\section{Children}

The Paediatric IBD Porto Group of European Society for Paediatric Gastroenterology Hepatology and Nutrition has differentiated pediatric IBD into 5 categories: typical UC, atypical UC, IBD-unclassified (IBDU), Crohn's colitis, and CD. ${ }^{95}$ While pancolitis is the predominant phenotype for UC, inflammatory ileo-colonic disease is the commonest presentation in CD. Pediatric-onset IBDU is twice as common as adult-onset disease.

Prolonged maintenance of corticosteroid-free remission and mucosal healing aids in improved growth in children with IBD. Clinical remission in pediatric IBD can be maintained with 5-ASA, thiopurines or biologics. Use of thiopurines is associated with decreased rates of hospitalization, corticosteroid use, and surgery in both UC and CD; but they are reserved as a second line therapy in children due to unfavorable safety profile. Adverse effects may occur in $15 \%-28 \%$ of pediatric IBD patients, and up to $18 \%$ may require discontinuation of therapy due to the same. In addition, there is an increased risk of infections, HSTCL, EBV positive mononucleosis associated T cell lymphoma and NMSC in young patients. Therefore, thiopurines should be used with caution with regular moni-

Table 7. Screening and Monitoring for Malignancy in IBD Patients Receiving Thiopurines

\begin{tabular}{ll}
\hline Lymphoma/leukemia & $\begin{array}{l}\text { Screen for EBV infection before initiating thiopurines } \\
\text { Monitor for development of signs and symptoms of possible lymphoma }\end{array}$ \\
Nonmelanoma skin cancer & $\begin{array}{l}\text { Lifelong sun protection } \\
\text { Yearly surveillance by dermatologist }\end{array}$ \\
Cervical cancer & HPV vaccine against HPV types 16 and 18 to all females between the age of 9 and 26 years \\
& Regular Pap smear examination as per gynaecologists' recommendation \\
Colorectal cancer & Screening colonoscopy 8 to 10 years after the IBD diagnosis, and surveillance colonoscopy every 1 to 2 years thereafter \\
\hline
\end{tabular}

EBV, Epstein-Barr virus; HPV, human papillomavirus; IBD, inflammatory bowel disease. 
toring of blood counts and liver enzymes (as discussed for adults) and close watch on development of malignancies. ${ }^{96-98}$

\section{COVID-19}

During the current pandemic of coronavirus disease 2019 (COVID-19), continuation of thiopurines and other immunosuppressive agents which can theoretically increase the risk of infections is a major concern. However, the currently available evidence does not suggest increased risk of COVID-19 in patients with IBD as compared to non-IBD patients. ${ }^{99}$ It is noteworthy that COVID-19 disease severity is characterized by increased levels of various cytokines (interleukins [IL-2, IL-6, IL7], granulocyte-colony stimulating factor, TNF- $\alpha$, etc.). ${ }^{100}$ This cytokine storm in COVID-19 resembles the cytokine profile of inflamed intestine in IBD. Hence, suppression of cytokines by thiopurines may in fact be beneficial for pulmonary complications. Also, as thiopurines act by incorporating into DNA/RNA of the leucocytes, it may take months for complete elimination of these agents from the body. So stopping thiopurines may not be worthwhile to tide over short-term situations. Hence at the moment, it is not recommended to stop/withdraw thiopurines and patients should continue all the scheduled medications. There are emerging data that thiopurines do not increase the risk of incident COVID-19 or cause worse outcomes of COVID-19 in IBD patients. ${ }^{101,102}$ However, close observation and monitoring is required if thiopurines are used in combination with biologics, particularly if started within 6 weeks. ${ }^{103}$

\section{Vaccination for Patients with IBD Receiving Thiopurines}

As there is an increased risk of infections in patients on thiopurines, vaccination is recommended for all patients with IBD prior to initiation of immunosuppression (Tables 1, 2). Live

Table 8. Key Learning Points

1. Thiopurines are effective for maintenance of remission for CD and UC.

2. An elaborate clinical workup is required for initiating and monitoring therapy with thiopurines.

3. Screening for infections like HBV, HCV, VZV, and EBV is recommended.

4. Daily doses of AZA, 6-MP and 6-TG are 2-3 mg/kg, 1-1.5 mg/kg, and 0.2-0.3 mg/kg respectively. Lower doses of AZA ( $<2 \mathrm{mg} / \mathrm{kg} / \mathrm{day}$ ) are effective in Asians. Combination of low dose thiopurines and allopurinol can be used in patients who are hypermethylators with 6-MMPR: 6-TGN ratio > 11. Genetic testing for polymorphisms in TPMT and NUDT15 can guide about the starting dose and predict dose-dependent adverse effects.

5. Combination of thiopurines with IFX is superior to either therapy alone in inducing remission in both UC and CD. Thiopurines decrease the formation of anti-drug antibodies and thereby improve the clinical efficacy of IFX. Evidence for combining AZA with adalimumab is not convincing. Concomitant use of thiopurines with vedolizumab and ustekinumab is not recommended at the moment.

6. Thiopurines have a narrow therapeutic window, therefore monitoring of treatment is required for optimization of therapy and prevent adverse effects. 6-TGN and 6-MMPR are the 2 metabolites measured in clinical practice to guide therapy. Mean corpuscular volume may be considered a surrogate marker for thiopurine metabolites where drug metabolite levels are not available/affordable.

7. Thiopurine use is associated with development of both idiosyncratic and dose-dependent adverse effects. Idiosyncratic adverse effects include fatigue, flu like illness, myalgias, gastrointestinal intolerance, headache, and pancreatitis whereas leucopenia, myelosuppression and hepatotoxicity are dose-dependent adverse effects.

8. Thiopurines carry a risk of development of malignancy. Lymphoma (non-Hodgkin lymphoma, NHL) is the commonest malignancy, usually seen in elderly patients receiving thiopurines. The risk decreases gradually after withdrawal of therapy. Hepatosplenic T cell lymphoma is a peripheral T cell lymphoma that occurs in young males receiving combination therapy with thiopurines and anti-TNF agents for $\geq 2$ years. Thiopurines increase the risk of development of primary EBV infection (especially in seronegative patients) which can progress to an aggressive and fatal lymphoma. Thiopurines should therefore be avoided in EBV seronegative patients. There is also an increased risk of nonmelanoma skin cancer and uterine cervical cancer.

9. Pregnancy in patients with IBD should be planned when the disease is in clinical remission. Thiopurines can be continued during pregnancy and lactation.

10. Thiopurine use in elderly ( $\geq 60$ years) is associated with increased risk of adverse effects including infections and malignancies and therefore should be used with caution.

11. Thiopurines can be continued in patients with IBD at risk for COVID-19.

12. Vaccination with live (except MMR) and inactivated vaccines is recommended.

CD, Crohn's disease; UC, ulcerative colitis; HBV, hepatitis B virus; HCV, hepatitis C virus; VZV, varicella zoster virus; EBV, Epstein-Barr virus; $A Z A$, azathioprine; 6-MP, 6-mercaptopurine; 6-TG, 6-thioguanine; 6-MMPR, 6-methyl mercaptopurine ribonucleotides; 6-TGN, 6-thioguanine nucleotides; TPMT, thiopurine-S-methyltransferase; NUDT15, nucleoside diphosphate-linked moiety X-type motif 15; IFX, infliximab; TNF, tumor necrosis factor; IBD, inflammatory bowel disease; COVID-19, coronavirus disease 2019; MMR, measles mumps rubella. 
vaccines against zoster and varicella are considered safe for use in patients on thiopurines, however measles mumps rubella vaccine is contraindicated and should be given either 3 to 6 weeks before starting thiopurines or at least 3 months after stopping the drug. Inactivated vaccines can be administered irrespective of therapy with thiopurines, though it is preferable to administer them early ( 2 weeks before starting thiopurine therapy). ${ }^{104,105}$

\section{WHEN TO WITHDRAW THIOPURINE THERAPY?}

Withdrawing thiopurines in patients who are in sustained remission is a difficult decision. There is high cumulative risk of relapse after withdrawal of thiopurines in both CD and UC. Discontinuation of thiopurines was associated with an average 1-year relapse rate of $38 \%$ in CD and $53 \%$ in UC. ${ }^{106}$ In clinical practice, the decision to stop thiopurines should be individualized. Patients who are in sustained clinical remission with normal biomarkers of disease activity and sustained mucosal (endoscopic/histologic) healing may be considered for withdrawal of thiopurines after 4-5 years of treatment with subsequent close monitoring. In the elderly (age $>60$ years), thiopurines should preferably be withdrawn because of increased incidence of adverse effects, including the risk of developing malignancies. Long-term prospective studies are lacking and more data are needed to develop standardized protocols regarding duration of use of thiopurine.

\section{CONCLUSION}

Thiopurines remain a fundamental, efficacious and cost-effective component in the therapeutic armamentarium of IBD (Table 8). However, a detailed pre-therapy clinical and laboratory assessment (including pharmacogenetic markers) is essential before initiating thiopurines. Although benefits outweigh the risk in appropriately selected patients, adverse effects do develop and awareness of the potential complications (including infections and malignancies) and their screening and management protocols is necessary. Since long-term use of these agents is commonly required, strategies to minimize the drug toxicity while maintaining its efficacy are important.

In an era, when plenty of new drugs are being developed, one has to maintain a fine balance between "the new" and "the old." Choosing not the "best" but "right" is the need of the hour.

\section{ADDITIONAL INFORMATION}

\section{Funding Source}

The authors received no financial support for the research, authorship, and/or publication of this article.

\section{Conflict of Interest}

Bernstein CN was funded in part by the Bingham Chair in Gastroenterology. He consulted to Abbvie Canada, Janssen Canada, Pfizer Canada, Shire Canada, Takeda Canada, and received unrestricted educational grants from Abbvie Canada, Janssen Canada, Pfizer Canada, Shire Canada, and Takeda Canada. He has been on the speaker's bureau of Abbvie Canada, Janssen Canada, Medtronic Canada and Takeda Canada. He received a research grant from Abbvie Canada and contract grants from Abbvie, Janssen, Pfizer, Celgene, Roche, Boehringer Ingelheim. Mak JW has received grants from Janssen, the Hong Kong College of Physicians and the Hong Kong Society of Gastroenterology, outside the submitted work. Ng SC has received research grants from Abbvie and Ferring; Speaker's honorarium from Janssen, Takeda, Abbvie, Ferring, Tillotts, Menarini, Pfizer and Olympus. Hanauer S has received grants from Prometheus Labs; Abbvie; Amgen; Boehringer Ingelheim; Gilead; GSK; Janssen; Lilly; Pfizer; Roche; Samsung-Bioepis; Shire; Takeda. The other authors report no conflict of interest.

Sood A is an editorial board member of the journal but was not involved in the peer reviewer selection, evaluation, or decision process of this article. No other potential conflicts of interest relevant to this article were reported.

\section{Author Contribution}

Conceptualization: Midha V, Ahuja V, Sood A. Data curation: Singh A, Mahajan R, Kedia S, Dutta AK, Anand A, Bernstein CN, Desai D, Pai CG, Makharia G, Kaur K, Arkkila P, Dutta U, Midha V. Project administration: Sood A. Resources: Singh A, Mahajan R, Kedia S, Dutta AK, Anand A, Bernstein CN, Desai D, Pai CG, Makharia G, Tevethia HV, Mak JW, Kaur K, Peddi K, Ranjan MK, Arkkila P, Verma S, Dutta U. Supervision: Midha V, Sood A. Writing - original draft: Singh A, Midha V, Sood A. Writing - review \& editing: Singh A, Mahajan R, Kedia S, Dutta AK, Anand A, Bernstein CN, Desai D, Pai CG, Makharia G, Tevethia HV, Mak JW, Kaur K, Peddi K, Ranjan MK, Arkkila P, Kochhar R, Banerjee R, Sinha SK, Ng SC, Hanauer S, Verma S, Dutta U, Midha V, Mehta V, Ahuja V, Sood A. Approval of final manuscript: all authors. 


\section{ORCID}

Singh A

Mahajan R

Kedia S

Dutta AK

Anand A

Bernstein CN

Desai D

Pai CG

Makharia G

Tevethia HV

MakJW

Kaur K

Peddi K

Ranjan MK

Arkkila P

Kochhar R

Banerjee R

Sinha SK

$\mathrm{Ng}$ SC

Hanauer S

Verma S

Dutta U

Midha V

Mehta V

Ahuja V

Sood A https://orcid.org/0000-0001-7163-0454

https://orcid.org/0000-0001-6726-6151

https://orcid.org/0000-0002-5758-0144

https://orcid.org/0000-0002-5111-7861

https://orcid.org/0000-0003-2974-011X

https://orcid.org/0000-0001-8041-3574

https://orcid.org/0000-0002-9741-5549

https://orcid.org/0000-0003-4676-6282

https://orcid.org/0000-0002-2474-2194

https://orcid.org/0000-0001-6587-4137

https://orcid.org/0000-0001-5221-7349

https://orcid.org/0000-0002-0951-7415

https://orcid.org/0000-0002-4524-9366

https://orcid.org/0000-0003-2575-5971

https://orcid.org/0000-0003-2194-0424

https://orcid.org/0000-0002-4077-6474

https://orcid.org/0000-0002-3753-4933

https://orcid.org/0000-0001-8088-9935

https://orcid.org/0000-0002-6850-4454

https://orcid.org/0000-0002-3268-932X https://orcid.org/0000-0002-7874-5737 https://orcid.org/0000-0002-9435-3557 https://orcid.org/0000-0003-0192-3969 https://orcid.org/0000-0002-8867-9526 https://orcid.org/0000-0002-1577-0118 https://orcid.org/0000-0001-6961-6389

\section{REFERENCES}

1. GBD 2017 Inflammatory Bowel Disease Collaborators. The global, regional, and national burden of inflammatory bowel disease in 195 countries and territories, 1990-2017: a systematic analysis for the Global Burden of Disease Study 2017. Lancet Gastroenterol Hepatol 2020;5:17-30.

2. Qiu Y, Mao R, Zhang SH, et al. Safety profile of thiopurines in Crohn disease: analysis of 893 patient-years follow-up in a Southern China cohort. Medicine (Baltimore) 2015;94:e1513.

3. Eklund BI, Moberg M, Bergquist J, Mannervik B. Divergent activities of human glutathione transferases in the bioactivation of azathioprine. Mol Pharmacol 2006;70:747-754.

4. Dubinsky MC. Azathioprine, 6-mercaptopurine in inflammatory bowel disease: pharmacology, efficacy, and safety. Clin Gastroenterol Hepatol 2004;2:731-743.

5. Chande N, Townsend CM, Parker CE, MacDonald JK. Azathioprine or 6-mercaptopurine for induction of remission in Crohn's disease. Cochrane Database Syst Rev 2016;10:

\section{CD000545.}

6. Colombel JF, Sandborn WJ, Reinisch W, et al. Infliximab, azathioprine, or combination therapy for Crohn's disease. N Engl J Med 2010;362:1383-1395.

7. Chande N, Patton PH, Tsoulis DJ, Thomas BS, MacDonald JK. Azathioprine or 6-mercaptopurine for maintenance of remission in Crohn's disease. Cochrane Database Syst Rev 2015;(10):CD000067.

8. Mantzaris GJ, Christidou A, Sfakianakis M, et al. Azathioprine is superior to budesonide in achieving and maintaining mucosal healing and histologic remission in steroid-dependent Crohn's disease. Inflamm Bowel Dis 2009;15:375382.

9. Singh S, Garg SK, Pardi DS, Wang Z, Murad MH, Loftus EV Jr. Comparative efficacy of pharmacologic interventions in preventing relapse of Crohn's disease after surgery: a systematic review and network meta-analysis. Gastroenterology 2015; 148:64-76.

10. Gjuladin-Hellon T, Iheozor-Ejiofor Z, Gordon M, Akobeng AK. Azathioprine and 6-mercaptopurine for maintenance of surgically-induced remission in Crohn's disease. Cochrane Database Syst Rev 2019;8:CD010233.

11. Regueiro M, Velayos F, Greer JB, et al. American Gastroenterological Association institute technical review on the management of Crohn's disease after surgical resection. Gastroenterology 2017;152:277-295.

12. Klein M, Binder HJ, Mitchell M, Aaronson R, Spiro H. Treatment of Crohn's disease with azathioprine: a controlled evaluation. Gastroenterology 1974;66:916-922.

13. Present DH, Korelitz BI, Wisch N, Glass JL, Sachar DB, Pasternack BS. Treatment of Crohn's disease with 6-mercaptopurine: a long-term, randomized, double-blind study. N Engl J Med 1980;302:981-987.

14. Steele SR, Kumar R, Feingold DL, Rafferty JL, Buie WD; Standards Practice Task Force of the American Society of Colon and Rectal Surgeons. Practice parameters for the management of perianal abscess and fistula-in-ano. Dis Colon Rectum 2011;54:1465-1474.

15. Ford AC, Luthra P, Hanauer SB, Travis SP, Harris MS, Reinisch W. Placebo response rate in clinical trials of fistulizing Crohn's disease: systematic review and meta-analysis. Clin Gastroenterol Hepatol 2014;12:1981-1990.

16. Torres J, Bonovas S, Doherty G, et al. ECCO guidelines on therapeutics in Crohn's disease: medical treatment. J Crohns Colitis 2020;14:4-22.

17. Lee MJ, Parker CE, Taylor SR, et al. Efficacy of medical thera- 
pies for fistulizing Crohn's disease: systematic review and meta-analysis. Clin Gastroenterol Hepatol 2018;16:18791892.

18. Sood A, Midha V, Sood N, Kaushal V. Role of azathioprine in severe ulcerative colitis: one-year, placebo-controlled, randomized trial. Indian J Gastroenterol 2000;19:14-16.

19. Ardizzone S, Maconi G, Russo A, Imbesi V, Colombo E, Bianchi Porro G. Randomised controlled trial of azathioprine and 5-aminosalicylic acid for treatment of steroid dependent ulcerative colitis. Gut 2006;55:47-53.

20. Maté-Jiménez J, Hermida C, Cantero-Perona J, MorenoOtero R. 6-Mercaptopurine or methotrexate added to prednisone induces and maintains remission in steroid-dependent inflammatory bowel disease. Eur J Gastroenterol Hepatol 2000;12:1227-1233.

21. Khan KJ, Dubinsky MC, Ford AC, Ullman TA, Talley NJ, Moayyedi P. Efficacy of immunosuppressive therapy for inflammatory bowel disease: a systematic review and metaanalysis. Am J Gastroenterol 2011;106:630-642.

22. Panaccione R, Ghosh S, Middleton S, et al. Combination therapy with infliximab and azathioprine is superior to monotherapy with either agent in ulcerative colitis. Gastroenterology 2014;146:392-400.

23. Sood A, Kaushal V, Midha V, Bhatia KL, Sood N, Malhotra V. The beneficial effect of azathioprine on maintenance of remission in severe ulcerative colitis. J Gastroenterol 2002;37: $270-274$

24. Timmer A, Patton PH, Chande N, McDonald JW, MacDonald JK. Azathioprine and 6-mercaptopurine for maintenance of remission in ulcerative colitis. Cochrane Database Syst Rev 2016;2016:CD000478.

25. Feuerstein JD, Isaacs KL, Schneider Y, et al. AGA clinical practice guidelines on the management of moderate to severe ulcerative colitis. Gastroenterology 2020;158:1450-1461.

26. Park SK, Yang SK, Ye BD, et al. The long-term efficacy of azathioprine in steroid-dependent ulcerative colitis. Scand J Gastroenterol 2013;48:1386-1393.

27. Goel RM, Blaker P, Mentzer A, Fong SC, Marinaki AM, Sanderson JD. Optimizing the use of thiopurines in inflammatory bowel disease. Ther Adv Chronic Dis 2015;6:138-146.

28. Sood A, Midha V, Sood N, Bansal M. Long term results of use of azathioprine in patients with ulcerative colitis in India. World J Gastroenterol 2006;12:7332-7336.

29. Sood R, Ansari S, Clark T, Hamlin PJ, Ford AC. Long-term efficacy and safety of azathioprine in ulcerative colitis. J Crohns Colitis 2015;9:191-197.
30. Lennard L, Chew TS, Lilleyman JS. Human thiopurine methyltransferase activity varies with red blood cell age. Br J Clin Pharmacol 2001;52:539-546.

31. European Association for the Study of the Liver. EASL 2017 Clinical Practice Guidelines on the management of hepatitis B virus infection. J Hepatol 2017;67:370-398.

32. Viazis N, Vlachogiannakos J, Georgiou O, et al. Course of inflammatory bowel disease in patients infected with human immunodeficiency virus. Inflamm Bowel Dis 2010;16:507511.

33. Gidrewicz D, Lehman D, Rabizadeh S, Majlessipour F, Dubinsky M. Primary EBV infection resulting in lymphoproliferative disease in a teenager with Crohn disease. J Pediatr Gastroenterol Nutr 2011;52:103-105.

34. N'guyen Y, Andreoletti L, Patey M, et al. Fatal Epstein-Barr virus primo infection in a 25-year-old man treated with azathioprine for Crohn's disease. J Clin Microbiol 2009;47:12521254.

35. Lam GY, Halloran BP, Peters AC, Fedorak RN. Lymphoproliferative disorders in inflammatory bowel disease patients on immunosuppression: lessons from other inflammatory disorders. World J Gastrointest Pathophysiol 2015;6:181-192.

36. Collie-Duguid ES, Pritchard SC, Powrie RH, et al. The frequency and distribution of thiopurine methyltransferase alleles in Caucasian and Asian populations. Pharmacogenetics 1999;9:37-42.

37. Kim JH, Cheon JH, Hong SS, et al. Influences of thiopurine methyltransferase genotype and activity on thiopurine-induced leukopenia in Korean patients with inflammatory bowel disease: a retrospective cohort study. J Clin Gastroenterol 2010;44:e242-e248.

38. Takatsu N, Matsui T, Murakami Y, et al. Adverse reactions to azathioprine cannot be predicted by thiopurine S-methyltransferase genotype in Japanese patients with inflammatory bowel disease. J Gastroenterol Hepatol 2009;24:12581264.

39. Ban H, Andoh A, Tanaka A, et al. Analysis of thiopurine Smethyltransferase genotypes in Japanese patients with inflammatory bowel disease. Intern Med 2008;47:1645-1648.

40. Shah SA, Paradkar M, Desai D, Ashavaid TF. Nucleoside diphosphate-linked moiety X-type motif 15 C415T variant as a predictor for thiopurine-induced toxicity in Indian patients. J Gastroenterol Hepatol 2017;32:620-624.

41. Schaeffeler E, Fischer C, Brockmeier D, et al. Comprehensive analysis of thiopurine S-methyltransferase phenotype-genotype correlation in a large population of German-Caucasians 
and identification of novel TPMT variants. Pharmacogenetics 2004; 14:407-417.

42. Liu Y, Meng Y, Wang L, Liu Z, Li J, Dong W. Associations between the NUDT15 R139C polymorphism and susceptibility to thiopurine-induced leukopenia in Asians: a meta-analysis. Onco Targets Ther 2018;11:8309-8317.

43. Relling MV, Schwab M, Whirl-Carrillo M, et al. Clinical pharmacogenetics implementation consortium guideline for thiopurine dosing based on TPMT and NUDT15 genotypes: 2018 update. Clin Pharmacol Ther 2019;105:1095-1105.

44. Xin H, Fischer C, Schwab M, Klotz U. Effects of aminosalicylates on thiopurine S-methyltransferase activity: an ex vivo study in patients with inflammatory bowel disease. Aliment Pharmacol Ther 2005;21:1105-1109.

45. Szumlanski CL, Weinshilboum RM. Sulphasalazine inhibition of thiopurine methyltransferase: possible mechanism for interaction with 6-mercaptopurine and azathioprine. Br J Clin Pharmacol 1995;39:456-459.

46. Blaker PA, Arenas-Hernandez M, Smith MA, et al. Mechanism of allopurinol induced TPMT inhibition. Biochem Pharmacol 2013;86:539-547.

47. Smith MA, Blaker P, Marinaki AM, Anderson SH, Irving PM, Sanderson JD. Optimising outcome on thiopurines in inflammatory bowel disease by co-prescription of allopurinol. J Crohns Colitis 2012;6:905-912.

48. Sultan KS, Berkowitz JC, Khan S. Combination therapy for inflammatory bowel disease. World J Gastrointest Pharmacol Ther 2017;8:103-113.

49. Atreya I, Diall A, Dvorsky R, et al. Designer thiopurine-analogues for optimised immunosuppression in inflammatory bowel diseases. J Crohns Colitis 2016;10:1132-1143.

50. Lichtenstein GR, Abreu MT, Cohen R, Tremaine W; American Gastroenterological Association. American Gastroenterological Association Institute medical position statement on corticosteroids, immunomodulators, and infliximab in inflammatory bowel disease. Gastroenterology 2006;130: 935-939

51. Seinen ML, van Asseldonk DP, Mulder CJ, de Boer NK. Dosing 6-thioguanine in inflammatory bowel disease: expertbased guidelines for daily practice. J Gastrointestin Liver Dis 2010;19:291-294.

52. Shi HY, Chan FK, Leung WK, et al. Low-dose azathioprine is effective in maintaining remission in steroid-dependent ulcerative colitis: results from a territory-wide Chinese population-based IBD registry. Therap Adv Gastroenterol 2016;9: 449-456
53. Pal P, Banerjee R. IDDF2018-ABS-0267 Azathioprine for maintenance of steroid-free remission: even a low dose is effective in Indian inflammatory bowel disease (IBD) patients. Gut 2018;67(Suppl 2):A87.

54. Roblin X, Boschetti G, Williet N, et al. Azathioprine dose reduction in inflammatory bowel disease patients on combination therapy: an open-label, prospective and randomised clinical trial. Aliment Pharmacol Ther 2017;46:142-149.

55. Shih DQ, Nguyen M, Zheng L, et al. Split-dose administration of thiopurine drugs: a novel and effective strategy for managing preferential 6-MMP metabolism. Aliment Pharmacol Ther 2012;36:449-458.

56. Lee KM, Kim YS, Seo GS, Kim TO, Yang SK; IBD Study Group of the Korean Association for the Study of Intestinal Diseases. Use of thiopurines in inflammatory bowel disease: a consensus statement by the Korean Association for the Study of Intestinal Diseases (KASID). Intest Res 2015;13:193-207.

57. Pavlidis P, Stamoulos P, Abdulrehman A, et al. Long-term safety and efficacy of low-dose azathioprine and allopurinol cotherapy in inflammatory bowel disease: a large observational study. Inflamm Bowel Dis 2016;22:1639-1646.

58. Matsumoto T, Motoya S, Watanabe K, et al. Adalimumab monotherapy and a combination with azathioprine for Crohn's disease: a prospective, randomized trial. J Crohns Colitis 2016;10:1259-1266

59. Hisamatsu T, Kato S, Kunisaki R, et al. Withdrawal of thiopurines in Crohn's disease treated with scheduled adalimumab maintenance: a prospective randomised clinical trial (DIAMOND2). J Gastroenterol 2019;54:860-870.

60. Boyapati RK, Torres J, Palmela C, et al. Withdrawal of immunosuppressant or biologic therapy for patients with quiescent Crohn's disease. Cochrane Database Syst Rev 2018;5:CD012540.

61. Kang B, Choi SY, Choi YO, et al. Subtherapeutic infliximab trough levels and complete mucosal healing are associated with sustained clinical remission after infliximab cessation in paediatric-onset Crohn's disease patients treated with combined immunosuppressive therapy. J Crohns Colitis 2018;12:644-652.

62. Moreau AC, Paul S, Del Tedesco E, et al. Association between 6-thioguanine nucleotides levels and clinical remission in inflammatory disease: a meta-analysis. Inflamm Bowel Dis 2014;20:464-471.

63. Yarur AJ, Kubiliun MJ, Czul F, et al. Concentrations of 6-thioguanine nucleotide correlate with trough levels of infliximab in patients with inflammatory bowel disease on combina- 
tion therapy. Clin Gastroenterol Hepatol 2015;13:1118-1124.

64. Vande Casteele N, Herfarth H, Katz J, Falck-Ytter Y, Singh S. American Gastroenterological Association institute technical review on the role of therapeutic drug monitoring in the management of inflammatory bowel diseases. Gastroenterology 2017;153:835-857.

65. Kennedy NA, Asser TL, Mountifield RE, Doogue MP, Andrews JM, Bampton PA. Thiopurine metabolite measurement leads to changes in management of inflammatory bowel disease. Intern Med J 2013;43:278-286.

66. Beswick L, Friedman AB, Sparrow MP. The role of thiopurine metabolite monitoring in inflammatory bowel disease. Expert Rev Gastroenterol Hepatol 2014;8:383-392.

67. Bouguen G, Sninsky C, Tang KL, et al. Change in erythrocyte mean corpuscular volume during combination therapy with azathioprine and infliximab is associated with mucosal healing: a post hoc analysis from SONIC. Inflamm Bowel Dis 2015;21:606-614.

68. Heerasing NM, Ng JF, Dowling D. Does lymphopenia or macrocytosis reflect 6-thioguanine levels in patients with inflammatory bowel disease treated with azathioprine or 6-mercaptopurine? Intern Med J 2016;46:465-469.

69. Feagan BG, Rutgeerts P, Sands BE, et al. Vedolizumab as induction and maintenance therapy for ulcerative colitis. $\mathrm{N}$ Engl J Med 2013;369:699-710.

70. Vasudevan A, Gibson PR, van Langenberg DR. Time to clinical response and remission for therapeutics in inflammatory bowel diseases: what should the clinician expect, what should patients be told? World J Gastroenterol 2017;23: 6385-6402.

71. Matsuoka K. NUDT15 gene variants and thiopurine-induced leukopenia in patients with inflammatory bowel disease. Intest Res 2020;18:275-281.

72. Gisbert JP, González-Lama Y, Maté J. Thiopurine-induced liver injury in patients with inflammatory bowel disease: a systematic review. Am J Gastroenterol 2007;102:1518-1527.

73. Gisbert JP, Luna M, González-Lama Y, et al. Liver injury in inflammatory bowel disease: long-term follow-up study of 786 patients. Inflamm Bowel Dis 2007;13:1106-1114.

74. Björnsson ES, Gu J, Kleiner DE, et al. Azathioprine and 6-mercaptopurine-induced liver injury: clinical features and outcomes. J Clin Gastroenterol 2017;51:63-69.

75. Shamberg L, Vaziri H. Hepatotoxicity of inflammatory bowel disease medications. J Clin Gastroenterol 2018;52:674-684.

76. Teich N, Mohl W, Bokemeyer B, et al. Azathioprine-induced acute pancreatitis in patients with inflammatory bowel dis- eases: a prospective study on incidence and severity. J Crohns Colitis 2016;10:61-68.

77. Bokemeyer B. Asymptomatic elevation of serum lipase and amylase in conjunction with Crohn's disease and ulcerative colitis. Z Gastroenterol 2002;40:5-10.

78. Ward MG, Patel KV, Kariyawasam VC, et al. Thioguanine in inflammatory bowel disease: long-term efficacy and safety. United European Gastroenterol J 2017;5:563-570.

79. Actis GC, Pellicano R, Rosina F. 6-Mercaptopurine for azathioprine intolerant inflammatory bowel disease: literature search and reappraisal of own data. Inflamm Allergy Drug Targets 2015;14:133-137.

80. Kirchgesner J, Lemaitre M, Carrat F, Zureik M, Carbonnel F, Dray-Spira R. Risk of serious and opportunistic infections associated with treatment of inflammatory bowel diseases. Gastroenterology 2018;155:337-346.

81. Toruner M, Loftus EV Jr, Harmsen WS, et al. Risk factors for opportunistic infections in patients with inflammatory bowel disease. Gastroenterology 2008;134:929-936.

82. Rahier JF, Ben-Horin S, Chowers Y, et al. European evidencebased Consensus on the prevention, diagnosis and management of opportunistic infections in inflammatory bowel disease. J Crohns Colitis 2009;3:47-91.

83. Kotlyar DS, Lewis JD, Beaugerie L, et al. Risk of lymphoma in patients with inflammatory bowel disease treated with azathioprine and 6-mercaptopurine: a meta-analysis. Clin Gastroenterol Hepatol 2015;13:847-858.

84. Kobayashi T, Uda A, Udagawa E, Hibi T. Lack of increased risk of lymphoma by thiopurines or biologics in Japanese patients with inflammatory bowel disease: a large-scale administrative database analysis. J Crohns Colitis 2020;14:617623.

85. Beaugerie L. Lymphoma: the bête noire of the long-term use of thiopurines in adult and elderly patients with inflammatory bowel disease. Gastroenterology 2013;145:927-930.

86. Lopez A, Mounier M, Bouvier AM, et al. Increased risk of acute myeloid leukemias and myelodysplastic syndromes in patients who received thiopurine treatment for inflammatory bowel disease. Clin Gastroenterol Hepatol 2014;12:13241329.

87. Ariyaratnam J, Subramanian V. Association between thiopurine use and nonmelanoma skin cancers in patients with inflammatory bowel disease: a meta-analysis. Am J Gastroenterol 2014;109:163-169.

88. Hutfless S, Fireman B, Kane S, Herrinton LJ. Screening differences and risk of cervical cancer in inflammatory bowel dis- 
ease. Aliment Pharmacol Ther 2008;28:598-605.

89. Bourrier A, Carrat F, Colombel JF, et al. Excess risk of urinary tract cancers in patients receiving thiopurines for inflammatory bowel disease: a prospective observational cohort study. Aliment Pharmacol Ther 2016;43:252-261.

90. Akbari M, Shah S, Velayos FS, Mahadevan U, Cheifetz AS. Systematic review and meta-analysis on the effects of thiopurines on birth outcomes from female and male patients with inflammatory bowel disease. Inflamm Bowel Dis 2013; 19:15-22.

91. Hutson JR, Matlow JN, Moretti ME, Koren G. The fetal safety of thiopurines for the treatment of inflammatory bowel disease in pregnancy. J Obstet Gynaecol 2013;33:1-8.

92. Bröms G, Granath F, Linder M, Stephansson O, Elmberg M, Kieler H. Birth outcomes in women with inflammatory bowel disease: effects of disease activity and drug exposure. Inflamm Bowel Dis 2014;20:1091-1098.

93. Mahadevan U, Robinson C, Bernasko N, et al. Inflammatory bowel disease in pregnancy clinical care pathway: a report from the American Gastroenterological Association IBD Parenthood Project Working Group. Gastroenterology 2019;156:1508-1524.

94. Juneja M, Baidoo L, Schwartz MB, et al. Geriatric inflammatory bowel disease: phenotypic presentation, treatment patterns, nutritional status, outcomes, and comorbidity. Dig Dis Sci 2012;57:2408-2415.

95. Levine A, Koletzko S, Turner D, et al. ESPGHAN revised porto criteria for the diagnosis of inflammatory bowel disease in children and adolescents. J Pediatr Gastroenterol Nutr 2014; 58:795-806.

96. Riello L, Talbotec C, Garnier-Lengliné H, et al. Tolerance and efficacy of azathioprine in pediatric Crohn's disease. Inflamm Bowel Dis 2011;17:2138-2143.

97. Turner D, Levine A, Escher JC, et al. Management of pediatric ulcerative colitis: joint ECCO and ESPGHAN evidencebased consensus guidelines. J Pediatr Gastroenterol Nutr
2012;55:340-361.

98. Ruemmele FM, Veres G, Kolho KL, et al. Consensus guidelines of ECCO/ESPGHAN on the medical management of pediatric Crohn's disease. J Crohns Colitis 2014;8:1179-1207.

99. Monteleone G, Ardizzone S. Are patients with inflammatory bowel disease at increased risk for Covid-19 infection? J Crohns Colitis 2020;14:1334-1336.

100. Mehta P, McAuley DF, Brown M, et al. COVID-19: consider cytokine storm syndromes and immunosuppression. Lancet 2020;395:1033-1034.

101. Khan N, Patel D, Xie D, Lewis J, Trivedi C, Yang YX. Impact of anti-tumor necrosis factor and thiopurine medications on the development of COVID-19 in patients with inflammatory bowel disease: a nationwide veterans administration cohort study. Gastroenterology 2020;159:1545-1546.

102. Brenner EJ, Ungaro RC, Gearry RB, et al. Corticosteroids, but not TNF antagonists, are associated with adverse COVID-19 outcomes in patients with inflammatory bowel diseases: results from an international registry. Gastroenterology 2020;159:481-491.

103. Rubin DT, Feuerstein JD, Wang AY, Cohen RD. AGA clinical practice update on management of inflammatory bowel disease during the COVID-19 pandemic: expert commentary. Gastroenterology 2020;159:350-357.

104. Farraye FA, Melmed GY, Lichtenstein GR, Kane SV. ACG clinical guideline: preventive care in inflammatory bowel disease. Am J Gastroenterol 2017;112:241-258.

105. Rubin LG, Levin MJ, Ljungman P, et al. 2013 IDSA clinical practice guideline for vaccination of the immunocompromised host. Clin Infect Dis 2014;58:309-318.

106. Torres J, Boyapati RK, Kennedy NA, Louis E, Colombel JF, Satsangi J. Systematic review of effects of withdrawal of immunomodulators or biologic agents from patients with inflammatory bowel disease. Gastroenterology 2015;149: 1716-1730. 